\title{
Interstitial laser photocoagulation of normal lung parenchyma in rats
}

\author{
D I Fielding, G Buonaccorsi, A Hanby, M R Hetzel, S G Bown
}

National Medical

Laser Centre, Department of Surgery, University College London Medical School, London, UK D I Fielding G Buonaccorsi S G Bown

Department of Thoracic Medicine, University College

London Hospitals, London, UK

D I Fielding

M R Hetzel

Department of Histopathology, Imperial Cancer Research Fund, London, UK A Hanby

Correspondence to: Dr D I Fielding, Department of Respiratory Medicine, Princess Alexandra Hospital, Ipswich Road,

Woolloongabba, Brisbane, Queensland 4102, Australia.

Received 15 December 1997 Returned to authors 22 January 1998

Revised manuscript received 17 March 1998

Accepted for publication

3 April 1998

\begin{abstract}
Background-Management of peripheral lung tumours may be risky in patients with poor lung function or in the elderly. A new possibility is interstitial laser photocoagulation (ILP) in which tumours are gently coagulated using thin laser fibres placed percutaneously under radiological guidance. This could have a useful palliative role in selected patients, but to be safe the effects on normal lung parenchyma must first be understood. This paper describes the creation and healing of ILP lesions in the normal rat lung.

Methods-ILP was performed using single laser fibres placed percutaneously in the left lung of normal rats under general anaesthetic with radiological guidance (laser power 1-3 W at $805 \mathrm{~nm}$, treatment time 250-1000 s). The lesion size and healing were studied in rats killed at times from three days to six months after treatment, the bursting pressure was measured, and any complications noted.

Results-Zones of necrosis up to $12 \mathrm{~mm}$ in diameter were produced, the size depending on the laser power and treatment time. Histological examination showed typical thermal effects with complete healing with fibrosis by two months. The effect was very localised with remarkably little effect on the structure and function of the rest of the lung. Adverse effects in the lung parenchyma only occurred if the ILP lesion involved the hilar vessels or the oesophagus, causing pulmonary congestion and perforation, respectively. Pneumothorax was seen in $6 \%$ of cases.

Conclusions-ILP with a single fibre can produce a localised zone of necrosis in normal lung parenchyma which heals safely and which has little effect on the rest of the lung. Further study of this technique using multiple fibres in a larger animal model is warranted to see if it is feasible and safe to produce a large enough volume of necrosis to be of value in the treatment of small peripheral lung tumours in patients who are unsuitable for surgery or palliative radiotherapy.

(Thorax 1998;53:692-697)
\end{abstract}

Keywords: interstitial laser photocoagulation; non-small cell lung cancer; minimally invasive percutaneous therapy

The NdYAG laser has been used on the lung parenchyma as a cutting tool, most commonly to assist in lesser tumour resections performed via open thoracotomy or video assisted thoracoscopic surgery (VATS) techniques. ${ }^{1}$ In this paper we have investigated the possibility of using laser energy alone to create a focal zone of necrosis within the lung parenchyma via a closed percutaneous technique known as interstitial laser photocoagulation (ILP). ILP uses low power laser light delivered directly into the tumour via fibres placed percutaneously under radiological guidance to produce localised thermal necrosis. ${ }^{2}{ }^{3}$ Unlike the NdYAG laser which is used at high power $(30-50 \mathrm{~W})$ for cutting, ILP uses low powers (2-3 W) and coagulates tissues in minutes rather than seconds. Experimental work on ILP in the liver ${ }^{4}$ and prostate $^{5}$ have shown zones of necrosis of predictable size which healed safely. The morphology of the effects on tumours was indistinguishable from those on normal tissues. The technique has since been used to treat tumours of these organs. ${ }^{6}$ In the liver tumours up to 4 $\mathrm{cm}$ in diameter can be necrosed in this manner using multiple fibres activated simultaneously.

For the lung the concept is to place similar fibres percutaneously into a peripheral tumour as for a fine needle aspiration biopsy. The technique would have primarily a palliative role as, for example, in patients with haemoptysis or cough where radiotherapy has not controlled the symptoms or cannot be given due to poor lung function. It would be less likely to have a curative role for stage 1 tumours as most patients with peripheral tumours who have poor lung function can be offered lesser resections such as a segmentectomy either by VATS or open procedures. ${ }^{78}$ Rates of local recurrence of tumour with lesser resections are, however, higher than for lobectomy. ${ }^{9}$ Potentially curative radiotherapy is another option for these patients, but radiation pneumonitis and incomplete tumour responses remain problematic. ${ }^{10-12}$ There could be a role for ILP as a less invasive alternative to metastasectomy. ${ }^{13}$

For ILP to be effective the treatment area must incorporate some macroscopically normal tissue surrounding the lesion as this is likely to contain microscopic tumour deposits. ${ }^{14}$ However, if normal tissue is to be treated, it is important that the effects are understood and known to heal safely. This paper assesses the acute effects of ILP in normal lung parenchyma and the healing process up to six months after treatment.

\section{Methods}

A near infrared diode laser of wavelength 805 $\mathrm{nm}$ (Diomed Ltd, Cambridge, UK) was used to deliver laser powers ranging from 1 to 3 


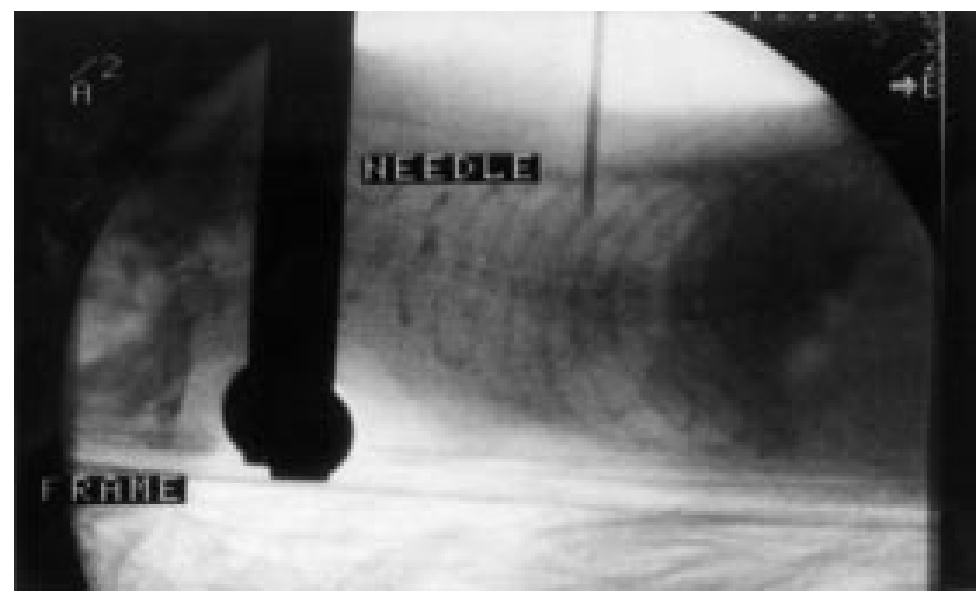

Figure 1 Fluoroscopic view of the fibre introducer needle placed into the left lung of a rat under general anaesthesia. mediastinum placed in formaldehyde. After three days the left lung was sectioned at approximately $1 \mathrm{~mm}$ intervals in a plane perpendicular to the line of the laser fibre insertion. Lesions were measured macroscopically by taking the largest diameter on these sections ${ }^{4}$ and necrosis was confirmed by histological examination of representative sections stained with haematoxylin and eosin.

Angiography was performed on a few animals to demonstrate the effects of ILP on parenchymal vessels. Immediately after sacrifice a cannula was placed into the main pulmonary trunk and secured. Normal saline was injected to flush out the blood, followed by 0.5 $\mathrm{ml}$ of a dilute mixture of barium and gelatin. When the gelatin solidified it kept the barium fixed in the vessels. Radiographs were then taken using mammography equipment.

In another group of animals the mechanical strength of the treated area was tested to assess the risk of pneumothorax due to the laser treatment and due to passage of the introducer needle across the lung surface. After killing the animals and removal of the lungs, a cannula was placed into the left main bronchus and ligated and the lung submerged in water in a metal frame. ${ }^{17}$ The lungs were inflated with air via a syringe mounted on a syringe driver. The pressure was slowly increased until air escaped from the lung surface as evidenced by bubbles escaping into the water. The pressure and volume at which this occurred were recorded and the site of rupture of the lung surface was noted.

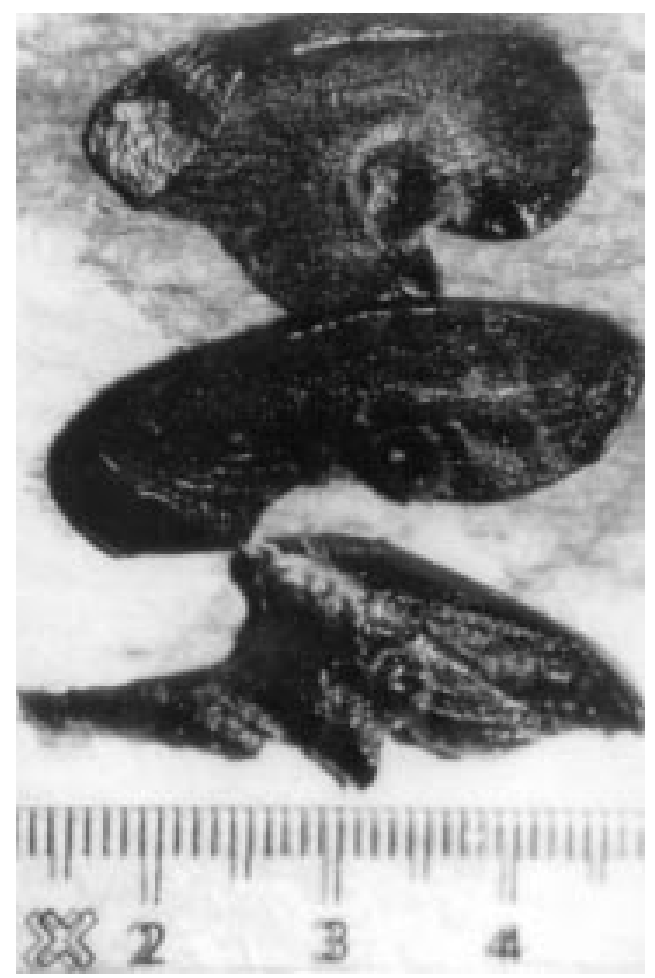

Figure 2 Macroscopic appearance of sections of lung cut perpendicular to the line of the fibre introducer into the lung three days after ILP using $2 \mathrm{~W}$ for 500 s. The zones of laser induced thermal necrosis are well demarcated from the adjacent areas of undamaged lung. 

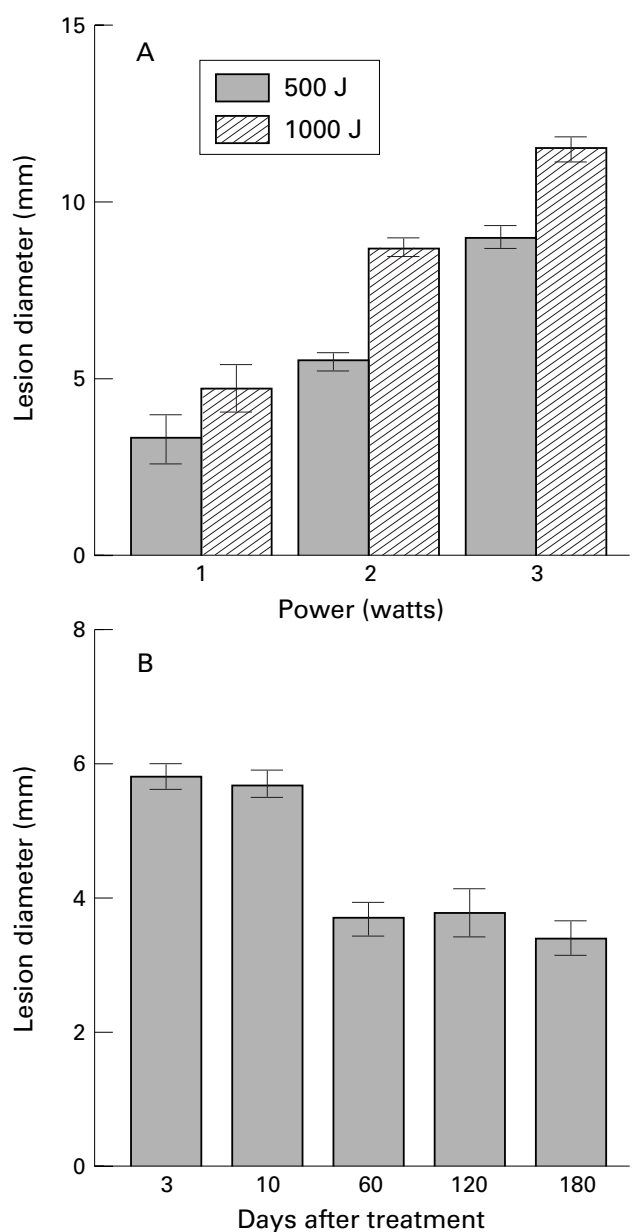

Figure 3 (A) Mean (SD) lesion sizes three days after ILP using different treatment variables. Data for each point come from at least three rats. (B) Mean (SD) lesion sizes at times up to six months after ILP using $2 W$ for $250 \mathrm{~s}$. Data for each point come from at least five rats.

\section{Results}

MACROSCOPIC APPEARANCE

ILP lung lesions were ellipsoid in shape with most of the effect seen close to the position of the fibre tip. Sections cut three days after treatment perpendicular to the direction of fibre

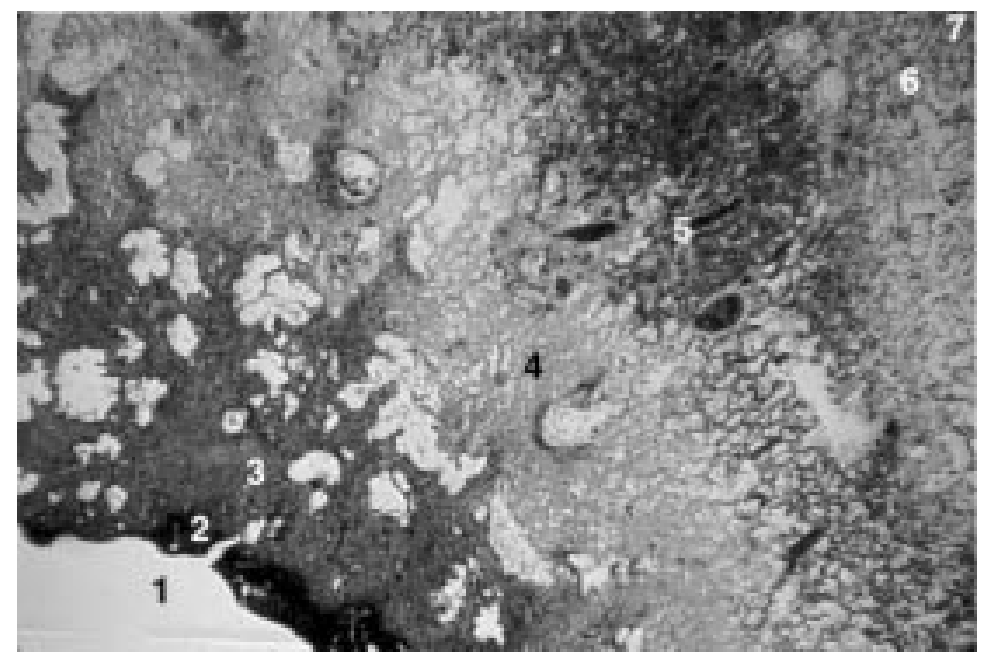

Figure 4 Haematoxylin and eosin stain of lesion three days after ILP using $2 \mathrm{~W}$ for $250 \mathrm{~s}$. Zones of necrosis are numbered 1-5 and zones of viable tissue are numbered 6-7. $1=$ central cavity; 2 = charring; 3 = condensed coagulated $z$ one $; 4=$ non-condensed coagulated zone; 5 = haemorrhagic necrosis; 6 = inflammation; $7=$ normal lung. insertion showed a central area of charred tissue surrounded by sequential rings of pale and haemorrhagic tissue (fig 2). There was a sharp demarcation between thermally damaged and normal tissue. Lesions were highly reproducible; for 10 lesions produced with $2 \mathrm{~W}$ for 500 seconds in animals killed at three days the mean lesion diameter was $8.7 \mathrm{~mm}$ with a standard deviation of $1.1 \mathrm{~mm}$. Figure 3A shows the mean lesion sizes at three days for different treatment parameters. The maximum diameter of necrosis seen was $12 \mathrm{~mm}$ using $3 \mathrm{~W}$ for 333 seconds.

By three weeks there was puckering of the lung surface and by two months the lesion had shrunk and the necrotic tissue had been predominantly replaced by white scar tissue. This process appeared complete by two months as there was no macroscopic difference in appearance of lesions at two and six months. Figure 3B shows the size of lesions at times up to six months following initial ILP treatment of $2 \mathrm{~W}$ for 250 seconds. In all except one case there was no adhesion between parietal and visceral pleura. In the one case where adhesions did occur, the parietal pleura had been inadvertently treated as well.

\section{HISTOLOGICAL APPEARANCE}

At three days histological examination showed a central charred zone with complete destruction of parenchyma including a small central cavity where tissue had been vapourised (fig 4). Surrounding this were two zones of eosinophilic coagulative necrosis with the more central zone showing a "condensed" appearance. This was consistent with immediate coagulation of proteins in this more central zone, with more gradual coagulative necrosis at the lower temperatures reached in the outer zone. In these zones necrosis was evident in alveolar walls as well as in bronchioles and small vessels. Surrounding this there was a perimeter of haemorrhagic tissue where leakage of red cells had occurred from sublethally injured small vessels. This was in contrast to the inner zones where the coagulating effect of the heat appeared to have sealed small vessels. There was a sharp cut-off between the laser lesions and normal lung. Outside this there was viable lung which contained an acute inflammatory cell infiltrate. Collagen and elastin stains showed complete destruction of connective tissue at the site of the lesion but no effect in the surrounding lung (fig 5). There was no extension of scar tissue into the surrounding parenchyma.

By 10 days the surrounding tissue was becoming organised into granulation tissue with an increase of fibroblasts and macrophages and dilatation of blood vessels at the perimeter of the lesion. There was persisting charred material in the centre. Associated with this were some deposits of foreign material, remnants of the silica fibre cladding, which were surrounded by foreign body giant cells. Bronchial walls which had been breached by the laser effect were starting to heal with replacement by granulation tissue. 


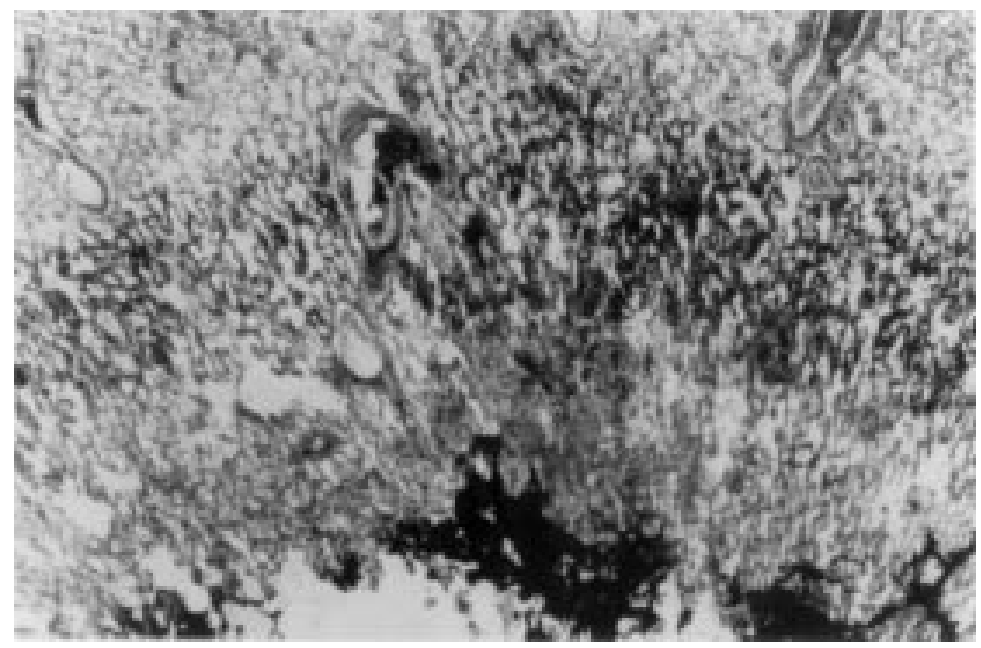

Figure 5 Reticulin stain of lesion three days after ILP showing the same zones as in fig 4 . Note the normal supporting tissue structure immediately surrounding the treated zone.

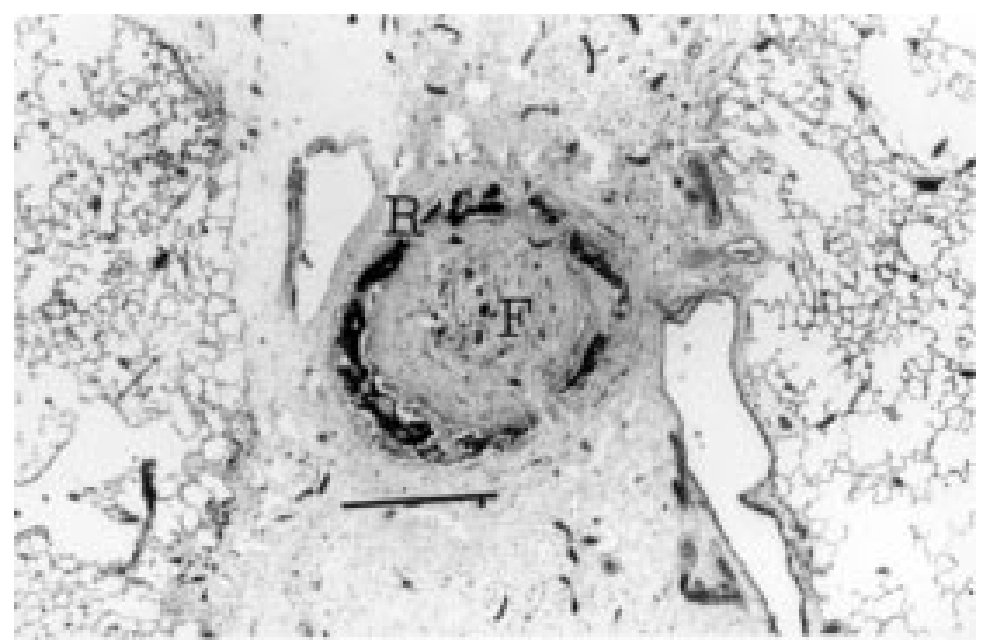

Figure 6 Histological appearance of lesion two months after ILP using $2 \mathrm{~W}$ for $250 \mathrm{~s}$. The section shows the site of treatment as a rim of charred debris $(R)$ with a central core of "young" cellular fibrous tissue $(F)$. Bar $=1 \mathrm{~mm}$.

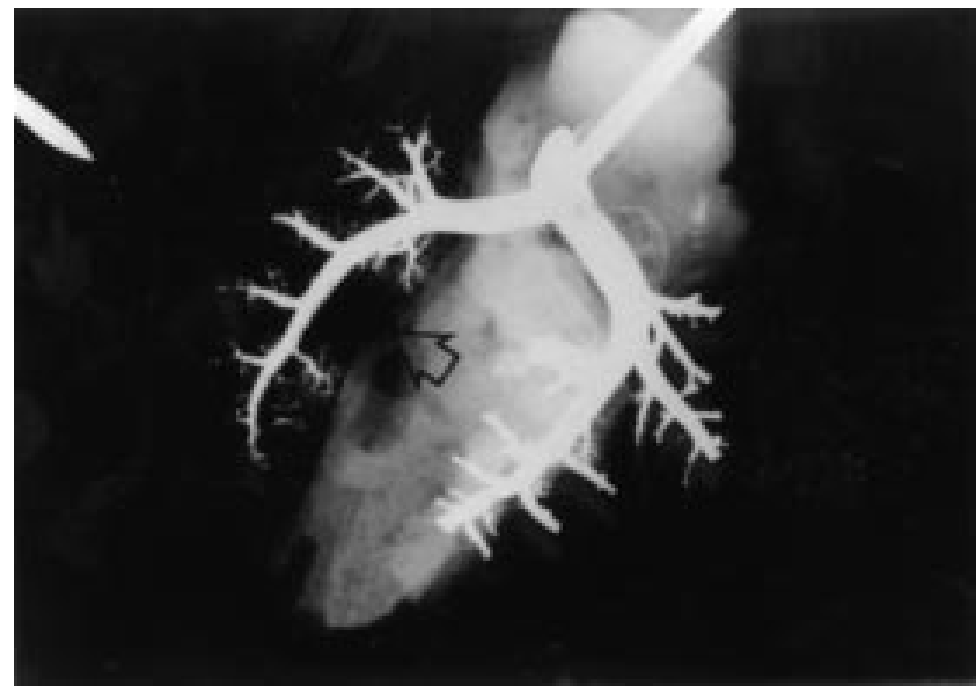

Figure 7 Pulmonary angiogram of lung treated with ILP showing loss of microvasculature at the site of the lesion (arrow).

At three weeks and two and six months there was progressive ingrowth of granulation tissue into and replacing the original area of necrosis. There was a sharp cut-off between the lesion
Table 1 Results of bursting pressure studies on control and treated lungs

\begin{tabular}{lll}
\hline & $\begin{array}{l}\text { Mean (SD) } \\
\text { bursting pressure } \\
\text { (mAtm) }\end{array}$ & $\begin{array}{l}\text { Number bursting } \\
\text { at site of } \\
\text { intervention }\end{array}$ \\
\hline $\begin{array}{l}\text { Controls } \\
\text { No intervention } \\
\text { Needle and fibre } \\
\text { immediate }\end{array}$ & $56(11)$ & $\begin{array}{l}\text { Not applicable } \\
6 \text { of } 7\end{array}$ \\
$\begin{array}{l}\text { ILP } \\
\text { Immediate }\end{array}$ & $36(20)$ & 2 of 6 \\
3 days & $43(12)$ & 1 of 6 \\
\hline
\end{tabular}

ILP $=$ interstitial laser photocoagulation.

and normal tissue. The whole lesion had contracted relative to its initial size and as a result there was some mild dilatation of airways and alveolar spaces in the immediately surrounding normal lung. The final appearance was of a nodule comprised of a ring of charred debris surrounding and surrounded by fibrosis (fig 6).

\section{ANGIOGRAPHY}

Angiograms were performed immediately after ILP in six rats. These showed obliteration of the microvasculature in the immediate vicinity of the treatment field (fig 7). In two cases the ILP lesion involved a central vessel which had been occluded, although no leakage of dye occurred indicating that the vessel had been sealed. Angiograms performed in four rats two months after ILP showed no disturbance of the vascular architecture.

\section{BURSTING PRESSURES}

Table 1 summarises the results of the bursting pressure studies. Untreated lungs tended to burst at the apex or on the lateral surface in the apical part of the lung. In the control animals, in which the needle and fibre were inserted but no laser energy was delivered, the lungs burst at the insertion site in six out of seven cases. In contrast, only two out of six burst at the site of ILP immediately after treatment. At three days only one of six burst at the site of ILP. In two of the cases that burst at the ILP lesion, the lesion passed from the outer to the inner surface of the lung creating a channel so that at no point was there overlying lung to seal it. Furthermore, the pressure at which these lesions burst was significantly higher than the bursting pressure of the six with needle insertion but no ILP (mean 49 mAtm compared with $28 \mathrm{mAtm}$, $\mathrm{p}<0.01)$. The pressures at which the ILP treated lungs burst (whether at the laser site or elsewhere) were comparable to the bursting pressure of control lungs which had had no intervention, although there was a wider range of bursting pressures for the treated lungs.

COMPLICATIONS

Of the 130 rats treated with ILP, 90 had no complications. Table 2 lists the complications which did occur. These were mainly related to the small size of the animal used in these experiments, which meant that the tip of the laser fibre was often close to major structures including the hilar vessels, major bronchi, and the oesophagus. Complications were less frequent in the later treatments as precision with 
Table 2 Complications of interstitial laser photocoagulation

\begin{tabular}{|c|c|c|c|c|c|}
\hline Time of complication & Immediate & $\begin{array}{l}\text { Up to } 3 \\
\text { days }\end{array}$ & $\begin{array}{l}\text { Up to } 3 \\
\text { weeks }\end{array}$ & $\begin{array}{l}\text { Up to } 6 \\
\text { months }\end{array}$ & Total \\
\hline Pneumothorax & $8(3)$ & & & & $8(3)$ \\
\hline Vascular effects & $5(5)$ & 4 & $2(2)$ & & $11(7)$ \\
\hline Lung and mediastinal infection due to oesophageal perforation & & $15(9)$ & $1(1)$ & 1 & $17(10)$ \\
\hline Lung abscess without oesophageal perforation & & & 2 & & 2 \\
\hline Lobar collapse & & & & 2 & 2 \\
\hline
\end{tabular}

Numbers in brackets indicate the number which had to be killed or died due to the complication. No rat had more than one complication.

placement of the fibre tip improved. By necessity, the lesions needed to be created near the oesophagus as most of the lung volume is located posteriorly.

The cause of pneumothorax in four rats was inadvertent treatment of the intercostal membrane creating a hole which allowed air to be drawn into the chest cavity. In two rats the laser lesion extended from the outer surface of the lung to the inner surface, creating an open channel. In one rat where the fibre was placed too deeply the main bronchus was perforated by the laser effect. Acute lung congestion peripheral to the laser lesion was seen in nine rats. In these animals the lesion was close to the hilum, coagulating the pulmonary vein draining the lower part of the lung; as a result capillaries and larger vessels distal to this showed intense engorgement. Five of these rats died during the procedure from extensive lung oedema. The remaining four did not show any effects of this complication but were sacrificed at three days for assessment of lesion size. Major haemorrhage due to laser penetration of vessels was not seen, even where the lesion was directly on a vessel. In two cases there was apparent infarction of a large segment of the lung due to ILP damage of the blood supply to that region. This caused significant breathlessness and malaise and necessitated sacrifice in both cases. In two rats there was collapse of a segment of the left lung distal to the ILP lesion which had obstructed the major bronchus.

Where the laser lesion was sited immediately adjacent to the oesophagus, a small perforation occurred in the wall of the oesophagus causing mediastinitis (fig 8). Late lung infections were

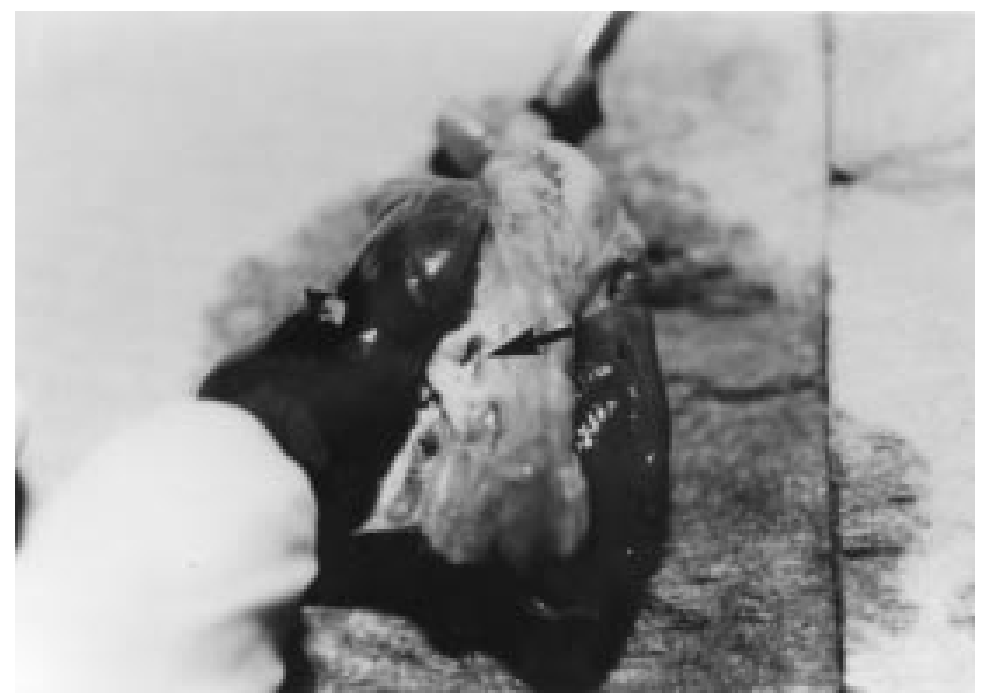

Figure 8 Oesophageal perforation occurring adjacent to an ILP lesion in the lung (arrow). seen in four rats after three weeks. Two of these were in animals with an oesophageal perforation. There was an associated lung abscess and food matter was seen in the lung parenchyma on histological examination, which showed full thickness scarring at the site of the laser lesion in the oesophagus. Two other rats developed a lung abscess at three weeks although a site of oesophageal perforation could not be located. As the lung lesion was close to the main bronchus in these rats a possible cause of the abscess was perforation of the main bronchus with subsequent seeding of infection into the lesion. To determine if prophylactic antibiotics could prevent lung and mediastinal infections, a further series of rats was given prophylactic broad spectrum antibiotics at the time of ILP and observed for up to two months. Three out of 12 rats developed late lung infections at times up to three weeks. An oesophageal perforation was found in all three.

\section{Discussion}

These studies have shown for the first time that it is possible to create a well defined zone of necrosis of reasonably predictable size within the lung parenchyma that heals safely using a percutaneous technique. This is what is required to treat a peripheral lung tumour and a ring of surrounding normal lung parenchyma using ILP.

The size of lesions in the lungs was comparable, although slightly smaller, than those seen with ILP in the normal liver, perhaps due to the aerated nature and high vascularity of the lung, both of which factors could be important in dissipating heat away from the lesion and consequently limiting its size. ${ }^{15}$ For a given laser power the lesion size reaches a plateau level with increasing treatment time as a result of an equilibrium between heating at the centre and cooling at the periphery due to blood flow. ${ }^{4}$ Further, ex vivo experiments in lung and liver have shown that the lesion becomes more elongated at powers above $3 \mathrm{~W}$ which is inappropriate for treating lung tumours which are usually spherical or ellipsoid in shape, and there is also more cavitation around the fibre tip at this power level. Thus, from our results, an appropriate power setting for lung ILP appears to be $2-3 \mathrm{~W}$ with an exposure time of 500-1000 seconds.

Histologically, the changes were typical of thermal injury in any tissue. ${ }^{418}$ The sequential zones of destruction outside the central carbonised region were due to progressively lower temperatures in zones located the further from the centre. As in similar studies on the liver, ${ }^{4}$ the small vessels in the treated area were com- 
pletely obliterated. Lesions healed safely by scarring limited to the site of injury without a residual cavity. The shrinkage of the lung seen two months after ILP was due to localised fibrous tissue contracture and did not have any marked effect on the volume of the treated lung or the respiratory rate (data not shown).

While complications have occurred in our experiments, we believe that these were due primarily to the small size of the animals used although verification of this is needed with a larger animal model. Clinically, it should be possible to reduce the risks by limiting treatment to tumours away from the oesophagus and central vessels and by careful placement of the fibres under CT guidance. Pneumothorax was uncommon given the relative size of the laser fibre and lesions to the size of the lung itself. By keeping the treated areas clear of the chest wall this problem is likely to be reduced even further in patients. The bursting pressure measurements suggested that ILP sealed the hole created in the lung surface by the introducer needle rather than enlarging it. Histologically, this sealing could have occurred in the coagulated zone immediately surrounding the centre of the laser lesion. All tissues shrink when treated with ILP and local shrinkage may also have contributed to sealing the hole. ${ }^{18}$ The same effect is seen when a higher power laser has been used in contact or non-contact mode to excise or ablate tissue in lung volume reduction surgery, after which histological examination and electron microscopy have shown condensation of collagen and elastin fibres, the histological correlate of sealing the sites of resection which is so important in preventing postoperative air leakage. ${ }^{19}$

The limited amount of fibrosis following ILP appears to be considerably less and much more localised than might be seen after radiotherapy. Each rat laser lesion involved about $13 \%$ of the volume of one lung, which is a higher percentage than would need to be destroyed to treat a $2 \mathrm{~cm}$ diameter lesion with a $2 \mathrm{~cm}$ zone of surrounding normal lung in a patient $(9 \%$ for a volume of $270 \mathrm{ml}$ in a typical single lung volume of $3000 \mathrm{ml}$ ). We also performed compliance studies which showed no significant changes at times up to six months after treatment (data not shown).

In summary, ILP can produce zones of necrosis up to $12 \mathrm{~mm}$ in diameter around single fibres in normal lung parenchyma which heal safely with localised fibrosis. These results suggest that the technique warrants further study in a larger animal model using multiple laser fibres to see if it is feasible and safe to produce a large enough volume of necrosis to be clinically useful.

This work was funded by the National Medical Laser Centre. There was no external funding.

1 Keenan RJ, Landreneau RJR, Hazelrigg SR, et al. Video thoracoscopic resection using the Nd YAG laser. $\mathcal{F}$ Thorac Cardiovasc Surg 1995;110:363-7.

2 Bown SG. Phototherapy of tumours. World f Surg 1983;7:700-9.

3 Steger AC, Lees WR, Walmsley K, et al. Interstitial laser hyperthermia: a new approach to local destruction of tumours. BMF 1989;299:362-5

4 Matthewson K, Coleridge-Smith P, O'Sullivan JP, et al. Bioogical effects of intrahepatic Nd-YAG laser photocoagulation in rats. Gastroenterology 1987;93:550-7.

5 McNicholas TA, Steger AC, Bown SG. Interstitial laser coagulation of the prostate. An experimental study. $B r \mathcal{F}$ Urol 1993;71:439-44.

6 Amin Z, Donald JJ, Masters A, et al. Hepatic metastases: interstitial laser photocoagulation with real time ultrasound monitoring and dynamic CT evaluation of treatment. Radiology 1993;187:339-47.

7 Shennib H, Landreneau RJ, Mack MJ. Video assisted thoracoscopic wedge resection of T1 lung cancer in high risk patients. Ann Surg 1993;218:555-60.

8 Ginsberg RJ, Rubenstein LV. Randomised trial of lobectomy versus limited resection for T1N0 non small cell cancer. Ann Thorac Surg 1995;60:615-23.

9 Landreneau RJ, Mack MJ, Dowling RD, et al. The role of thoracoscopy in lung cancer management. Chest 1998;113: $6 \mathrm{~S}-12 \mathrm{~S}$

10 Van Houtte P, Mornex F. Radiotherapy of non small cell lung cancer. In: Spiro S, ed. European Respiratory Monograph Vol 1. London: European Respiratory Journals Ltd, 1995: 241-68.

11 Mah K, Van Dyk J, Keane T, et al. Acute radiation-induced pulmonary damage: a clinical study on the response to pulmonary damage: a clinical study on the response to 1987;13:179.

12 Armstrong JG, Zelefsky MJ, Leibel SA, et al. Strategy for dose escalation using three dimensional conformal radiation therapy for lung cancer. Ann Oncol 1995;6:693-7.

13 Dowling RD, Landreneau RJ, Miller DL. Video assisted thoracoscopic surgery for resection of lung metastases. Chest 1998;113:2S-5S

14 McIntosh R, Thatcher N. Management of the solitary metastasis. Thorax 1990;45:909-11.

15 Amin Z, Buonaccorsi G, Mills T, et al. Interstitial laser photocoagulation. Evaluation of a $1320 \mathrm{~nm}$ Nd-YAG and an $805 \mathrm{~nm}$ diode laser: The significance of charring and the value of pre-charring the fibre tip. Lasers Med Sci 1993;8:113-20.

16 Freeman G, Crane SC, Furiosi NJ, et al. Covert reduction in ventilatory surface in rats during prolonged exposure to subacute nitrogen dioxide. Am Rev Respir Dis 1972;106: 563-79.

17 Scherle W. A simple method for volumetry of organs in quantitative stereology. Mikroskopie 1970;26:57-60.

18 Thomsen S. Pathological analysis of photothermal and photomechanical effects of laser-tissue interactions. Photochem Photobiol 1991;53:825-35.

19 Sawabata N, Nezu K, Tojo T, et al. Morphological examination of the lung tissue ablated with Nd YAG laser in the treatment of bullous pulmonary disease Geka-Gakkai-Zasshi 1995;43:831-5. 